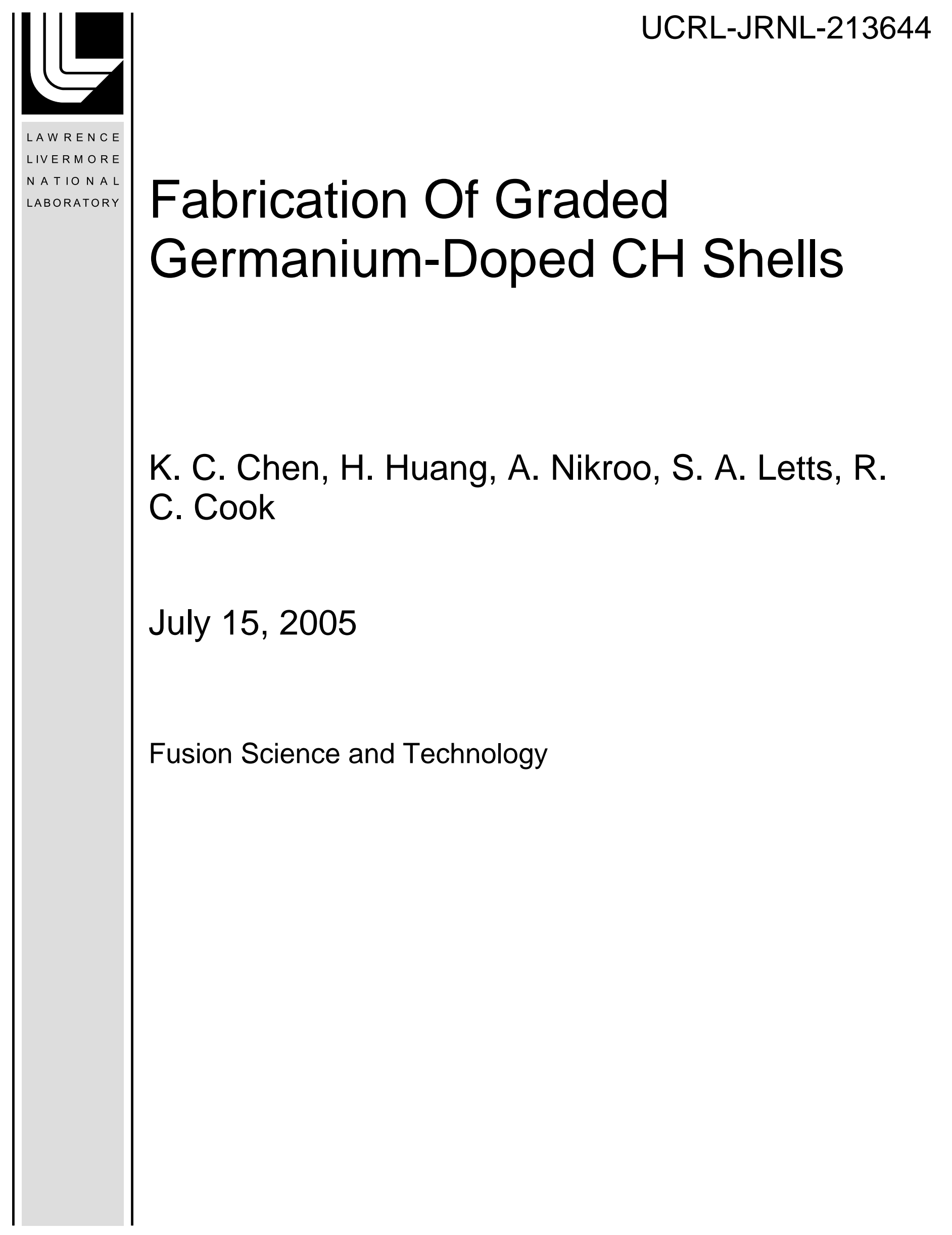


This document was prepared as an account of work sponsored by an agency of the United States Government. Neither the United States Government nor the University of California nor any of their employees, makes any warranty, express or implied, or assumes any legal liability or responsibility for the accuracy, completeness, or usefulness of any information, apparatus, product, or process disclosed, or represents that its use would not infringe privately owned rights. Reference herein to any specific commercial product, process, or service by trade name, trademark, manufacturer, or otherwise, does not necessarily constitute or imply its endorsement, recommendation, or favoring by the United States Government or the University of California. The views and opinions of authors expressed herein do not necessarily state or reflect those of the United States Government or the University of California, and shall not be used for advertising or product endorsement purposes. 


\title{
FABRICATION OF GRADED GERMANIUM-DOPED CH SHELLS
}

\author{
K.C. Chen, H. Huang, A. Nikroo, S.A. Letts, ${ }^{\dagger}$ and R.C. $\mathrm{Cook}^{\dagger}$ \\ General Atomics, P.O. Box 85608, San Diego, California 92186-5608 \\ $\dagger$ Lawrence Livermore National Laboratory, P.O. Box 808, Livermore, California 94550
}

\begin{abstract}
One of the current capsule designs for achieving ignition on the National Ignition Facility (NIF) is a $2 \mathrm{~mm}$ diameter graded Ge-doped CH shell that has a $160 \mu \mathrm{m}$ thick wall. The Ge doping is not uniform, but rather is in radial steps. This graded Ge-doped design allows rougher surface finish than the original undoped CH design thus has a less stringent new surface standard.
\end{abstract}

We selected quality mandrels by coating dozens of mandrel batches to $\sim 70 \mu \mathrm{m}$ thickness to amplify sub-micrometer defects on the mandrels and successively removed inferior batches. The Ge-doping layers are made by introducing $\left(\mathrm{CH}_{3}\right)_{4} \mathrm{Ge}$ to the gas stream. The doping concentrations were determined by performing tryout runs and characterized by X-ray fluorescence analyses and quantitative radiograph calculations, with good agreement between the methods being demonstrated.

The precise layer thickness and Ge concentrations were determined by a non-destructive quantitative contact radiograph. The as-coated shell has an inner $10 \mu \mathrm{m}$ undoped $\mathrm{CH}$ layer, followed by a 48 um thick 0.83 at. \% Ge-doped CH, 10 um thick 0.38 at. \% Ge-doped $\mathrm{CH}$ and then $90 \mu \mathrm{m}$ of undoped CH. The shell meets nearly all the NIF design thickness specifications and Ge concentrations. 
The atomic force microscope power spectrum of the shell meets the new NIF standard. The shells has a root-mean-square surface roughness of $\sim 24 \mathrm{~nm}$ (modes 100-1000). A few surface flaws are isolated domes of $1 \mu \mathrm{m}$ tall and $20 \mu \mathrm{m}$ in diameter.

Mandrel was successfully removed by pyrolysis at $305^{\circ} \mathrm{C}$ for $10-20 \mathrm{~h}$. After pyrolysis, the diameter and wall shrink $0.4 \%$ and $5.7 \%$, respectively. The shell's inner surface has root-meansquare roughness ranging from 1.1-6.5 nm by WYKO interferometer measurement. 


\section{INTRODUCTION}

Graded germanium-doped $\mathrm{CH}$ shell is the current plastics design for the National Ignition

Facility (NIF). ${ }^{1,2}$ Figure 1 shows the graded germanium-doped shell design. The graded shell has four layers with two middle layers contain low germanium doping levels at 0.75 at. \% and 0.38 at. $\%$. The shell is $\sim 2 \mathrm{~mm}$ in diameter and has a total wall thickness of $160 \mu \mathrm{m}$. It must meet demanding germanium concentrations within $\pm 10 \%$, layer thickness within $\pm 0.5 \mu \mathrm{m}$, and surface smoothness specification.

The $\mathrm{CH}$ shell has an advantage of surface can be fabricated very near NIF standards. As compared with beryllium shell, the $\mathrm{CH}$ shell has no microstructure and has transparent wall that allows optical characterization of ice layer. Also, IR heating is possible to enhance $\beta$ layering and $\mathrm{D}_{2}$ operation. There are also disadvantages include lower absorbed energy and larger short wavelength growth than graded copper dopant beryllium. ${ }^{2}$

This graded germanium-doped design tolerates rougher surface finish than the undoped shells, and therefore, has a less stringent surface smoothness standard. The new surface smoothness standard, shown in power spectrum versus modes, allows a factor of six increases in power over the original standard for the modes greater than 23 (Fig. 2). ${ }^{3}$ The germanium doping concentration for the graded shells is much less than the germanium doping that have been previously reported. ${ }^{3}$ The lower than 1 at. \% germanium doping level requires a very stable flow controller capable of flow control at less than $0.05 \mathrm{sccm}$.

\section{EXPERIMENTAL}

The Ge-doped $\mathrm{CH}$ ablator material is produced by plasma enhanced chemical vapor deposition of a polymer. In this process hydrogen and trans-2-butene gas are broken down in an 
inductively coupled plasma system onto high quality shells, referred as mandrels. ${ }^{4}$ The mandrel in typically made of poly- $\alpha$-methylstyrene (PAMS) produced by micro-encapsulation. ${ }^{5}$ The fragments deposit on the substrates and form a pure $\mathrm{CH}$ polymer film. The hydrogen flow is typically at $10 \mathrm{sccm}$ and trans-2-butene is at $0.17 \mathrm{sccm}$. Incorporation of germanium dopant is achieved by adding the vapor of tetramethyl germanium (TMG) in small flow rate, less than $0.05 \mathrm{sccm}$, to the gas stream. ${ }^{6}$ The relative concentration of TMG in the process controls the level of doping. A special flow differential pressure transducer (MKS 698A01TRB) that has full range of 1 Torr and controller (MKS Type 250) were used to control the low level germanium flow. The germanium doping concentrations were determined on shards from tryout run shells and characterized by X-ray fluorescence analyses (XRF). The coating rates versus germanium doping levels were established in order to achieve precise layer thickness. The coating rate is rather slow, $\sim 0.5 \mu \mathrm{m} / \mathrm{hr}$, requiring over two weeks to deposit the full NIF thickness of $160 \mu \mathrm{m}$.

Uniform coating of mandrels requires agitation during deposition of the $\mathrm{Ge}$-doped $\mathrm{CH}$ coating. Mandrels are placed in a pan attached to a tapping device that taps the pan every $30 \mathrm{~s}$ during the coating to provide the required agitation. ${ }^{7}$ Gentle tapping avoids the agitation-induced defects observed when piezo shaking technique was used ${ }^{8}$ Typically nine mandrels were coated in a single coating run.

The fabricated shells are characterized by a variety of techniques, including scanning electron microscope, white light interferometry and the atomic force microscope (AFM) spheremapper. The AFM spheremapper provides the most important metrology data and is typically used to evaluate the quality of the shell. The AFM spheremapper produced power spectra of the shells are compared to the desired spectrum, "the NIF standard", provided by current designs. 
The germanium concentrations and precise layer thickness were determined by quantitative contact radiography. The germanium atomic percent were determined by fitting the measured transmission profile with a model so that the calculated profile matches the measured profile. The details of the model and method used are described elsewhere in this issue. ${ }^{9}$ Radiograph data was compared and confirmed versus X-ray fluorescence.

Mandrel was removed at $305^{\circ} \mathrm{C}$ for $10 \mathrm{~h}$ in flowing nitrogen. The diameter, wall shrinkage and germanium concentrations of the pyrolyzed shells were also determined by quantitative radiograph. The surface quality was characterized by spheremapper and presented as power spectrum. The surface roughness of the inner wall was characterized with WYKO interferometer on fractured shell.

\section{RESults AND Discussions}

\section{III.A. Mandrel Selection}

It is known that high mode roughness or isolated defects present on the mandrels grow during the coating and degrade the surface finish of the full thickness shell. 9,10 To distinguish between mandrel defects and possible agitation induced defects, mandrels from several different batches were coated in the same coating run. We examined dozens of mandrel batches using shorter ( $\sim 6-7$ day, $\sim 70 \mu \mathrm{m}$ thickness) coating runs. Only mandrels from those batches with shells consistently meeting the "NIF standard" were used for coatings (Fig. 3). The fact that shells from some batches produced poorer surfaces than others indicated a problem with that particular batch.

Through this process we were able to identify several batches as being superior to others and only they were used in any further work. To further separate the cause of dome generation, 
coated shells from the remaining batches were coated for another week reaching full thickness. The number of domes detected after one and then two weeks of coating were counted and compared. Only a slight increase in the number of domes was observed in doubling the thickness, indicating the coating process was not the main source of dome generation. Several shells from the best mandrel batch were also completely spheremapped. The complete spheremaps show the possibility of a few micrometer-high defects presence on mandrel surface.

\section{III.B. Control of Germanium Dopant Concentrations}

Since the germanium doping levels are less than 1 at $\%$. The stability and reproducibility of the flow control is a main concern. The desired germanium controller settings were found by successively extrapolating and confirming with X-ray fluorescence on tryout runs. By repeating the tryout runs, we reduced the deviation of germanium concentration to around $10 \%$ for the same controller setting by using zero-corrected controller settings. The fluctuation increases to $\sim 17 \%$ below 0.3 at. $\%$ of germanium doping, where fluctuation and drifting of controller zero become significant.

\section{III.C. Control of Layer Thickness by Determining Coating Rates versus GERMANIUM CONCENTRATIONS}

The coating rate is a function of germanium concentration (Fig. 4). Using the tryout runs, we determined the coating rates for the two desired germanium doping levels to be 0.51 and $0.46 \mu / \mathrm{h}$ for 0.75 at. $\%$ and for 0.38 at. $\%$ Ge, respectively. Standard deviation of coating rates is at $0.03 \mu \mathrm{m} / \mathrm{h}$, which contributes thickness variations of $10 \%$. For the 45 and $90 \mu \mathrm{m}$ layers, the variation can be as large as 4.5 and $9 \mu \mathrm{m}$, which is higher than the tolerance of NIF specifications. Therefore, the coating run needs to be stopped for "break-point" measurements in order to have better thickness accuracy. 


\section{III.D. Characterization OF Graded Germanium-Doped ShellS}

We made the first batch of graded germanium-doped shells using the determined germanium flow controller settings and coating rates. The back-scattered scanning electron micrograph of the shell's cross-section clearly shows distinct layers due to atomic number contrast (Fig. 5). Two germanium-containing layers are brighter than the two un-doped layers. The brightest layer contains higher germanium concentration. The cross-section image is close to the design shown in Fig. 1. The X-ray contact radiograph image is shown in Fig. 6.

The measured normalized transmission intensity profile versus shell radius of the graded germanium shell is shown in Fig. 7. The zero transmission area, where full-exposure occurs, is outside the shell. The transmission curve shows a few discontinuities which delineate the layer boundaries. The layer thickness was precisely determined by using the second derivative of the transmission curve to $\pm 0.2 \mu \mathrm{m}$ when layer boundary is distinct. However, the boundary between and mandrel and the first layer of freshly-deposited un-doped $\mathrm{CH}$ is not clear due to their densities are very close (mandrel density 1.09 and $\mathrm{CH}$ density $1.08-1.1$ ). Because of this, the thickness error for the first $\mathrm{CH}$ layer is higher at $\pm 0.5 \mu \mathrm{m}$. Fortunately, we can verify the first layer thickness using white light interferometer measurement by stopping the coating run and perform a "break point" measurement.

The concentration model is based on the undoped $\mathrm{CH}$ layer consists of one carbon plus 1.4 hydrogen. This elemental composition is based on previous analyses of carbon and hydrogen on un-doped $\mathrm{CH}$. The density used for $\mathrm{CH}$ is $1.08-1.10$. These values give a very good match of the calculated curve with normalized transmission curve for the outer $\mathrm{CH}$ layer. The germanium atom percent was determined by incorporating germanium into un-doped $\mathrm{CH}$ so that the calculated curve match the measured normalized transmission profile. The densities of the 
germanium-doped layers, which were verified on single layer tryout runs, are $1.12 \mathrm{~g} / \mathrm{cc}$ for low Ge layer and 1.18 for high Ge concentration layers.

The quantitative radiograph result shows we have successfully produced a four-layered graded-Ge $\mathrm{CH}$ shells. The shells have an inner $10 \pm 0.5 \mu \mathrm{m}$ un-doped GDP layer, followed by a $48 \pm 0.2 \mu \mathrm{m} 0.83 \pm 0.09$ at. \% Ge-doped $\mathrm{CH}$, and $10 \mu \mathrm{m}$ thick $0.38 \pm 0.04$ at. \% Ge-doped $\mathrm{CH}$ and then $90 \pm 0.2 \mu \mathrm{m}$ of un-doped $\mathrm{CH}$. Except for the thickness of the top layer is slightly less than the design specification, the thickness three other layers and germanium doping concentrations are coated slight higher than the design specifications to account for the expected shrinkage after mandrel removal (Fig. 8).

We characterized the surface smoothness of the as-deposited graded germanium $\mathrm{CH}$ shell with atomic force microscope (AFM) spheremapper. The AFM traces show the shell is quite smooth for a $150 \mu \mathrm{m}$ thick shell (Fig. 9). Only one defect over $1 \mu \mathrm{m}$ was observed in the nine traces. Most defects are less than $300 \mathrm{~nm}$ in height. The power spectrum of the shell is below the new relaxed NIF standard (Fig. 10).

\section{III.E. REMOVAL OF MANDREL BY PYROLYSIS}

We have pyrolyzed the shells at $305^{\circ} \mathrm{C}$ for $10-20 \mathrm{~h}$ to remove the mandrel. The shells were again characterized by quantitative radiograph to see if dimensions and germanium concentrations are affected. Figure 9 shows the mandrel was successfully removed from the thick-walled shell and distinctive layered structure remains intact. The detailed analysis of the shell diameter, layer thickness and germanium concentration show there is $0.4 \%$ diameter shrinkage and $5.7 \%$ wall shrinkage. The concentrations, within the measurement error bar, did not change. We used WYKO interferometer and to examine the surface smoothness of inner 
wall. The measurements were carried out on pieces from fractured shells. The surface a rootmean-square surface roughness is ranging from 1.1 to $6.5 \mathrm{~nm}$.

\section{SUMMARY}

In summary, we have successfully fabricated the graded germanium-doped $\mathrm{CH}$ shells. The shells have been characterized by newly developed quantitative contact radiograph, which allows us to measure precise thickness and germanium dopant concentrations non-destructively.

The graded shell has an inner $10 \mu \mathrm{m}$ un-doped GDP layer, a $48 \mu \mathrm{m} 0.83$ at. \% Ge-doped $\mathrm{CH}$, a $10 \mu \mathrm{m}$ thick 0.38 at. \% Ge-doped $\mathrm{CH}$ and finally a top $90 \mu \mathrm{m}$ of un-doped $\mathrm{CH}$, which meet nearly all the NIF design thickness and germanium concentration requirements. Mandrel has been successfully removed by pyrolyzed. The smoothness of the inner surface was characterized by WYKO interferometer on pieces of fractured shells (Fig. 11). The root-mean-square surface roughness sampling over two $60 \mu \mathrm{m}$ by $46 \mu \mathrm{m}$ areas are ranging from 1.1 to $6.5 \mathrm{~nm}\left(305^{\circ} \mathrm{C}\right.$, $20 \mathrm{~h}$ ). The remaining issues are elimination of isolated defects and better in-situ layer thickness control to minimize shell handling.

\section{ACKNOWLedgment}

We would like to thank Jane Gibson for performing AFM spheremap and Samuel Eddinger and Meghan West for contact radiograph measurements. Work supported by U.S. Department of Energy under Contract DE-AC03-01SF22260 and under the auspices of the U.S. Department of Energy by the University of California Lawrence Livermore National Laboratory under Contract No. W-7405-Eng-48. 


\section{REFERENCES}

1. S. HANN et al., "Increasing Robustness of Indirect Drive Capsule Designs Against Short Wavelength Hydrodynamic Instabilities," Physics of Plasma 12, 056316 (2005) and M. HERMANN, A. FETTERMAN, S. HAAN, and J. SALMONSON, "Optimization of Indirect Drive Capsules of the National Ignition Facility,” presented at General Atomics, October 26, 2004.

2. S. HAAN, "Update on Specifications for NIF Ignition Targets, and Their Rollup into an Error Budget," presented at $16^{\text {th }}$ Target Fabrication Specialists Meeting, May 3, 2005

3. M. HERRMANN, private communication on Graded Ge new power spectrum standard.

4. S.A. LETTS et. al., "Fabrication of Polymer Shells Using a Depolymerizable Mandrel," Fusion Technol. 28, 17977 (1995).

5. A. NIKROO, J. BOUSQUET, R. COOK, B.W. MCQUILlAN, R. PAGUIO, M. TAKAGI, "Progress in 2 mm Glow Discharge Polymer Mandrel Development for NIF," Fusion Sci. Technol. 45, (2), 165 (2004).

6. R. BRUSASCO, M. SACULLA, AND R. COOK, "Preparation of Germanium Doped Plasma Polymerized Coatings as Inertial Confinement Fusion Target Ablators," J. Vac Sci. Technol. A 13, 948 (1995).

7. A. NIKROO and D.M. WOODHOUSE, "Bounce Coating Induced Domes on Glow Discharge Polymer Coated Shells," Fusion Technol. 35, 202 (1999)

8. A. NIKROO, J. PONTELANDOLFO, and E. CASTILLO, "Coating and Mandrel Effects on Fabrication of Glow Discharge Polymer NIF Scale Indirect Drive Capsules," Fus. Sci. Technol. 41, 220 (2002). 
9. H. Huang, R.B. Stephens, S.A. Eddinger, A. Nikroo, K.C. Chen, H.W. Xu, "Nondestructive Quantitative Dopant Profiling Technique by Contact Radiography" these proceedings.

10. S.A. LETTS, D.W. MYERS, and L.A. WITT, "Ultrasmooth Plasma Polymerized Coatings for Laser Fusion Targets,” J. Vac. Sci. Technol. 19, 739 (1981).

11. R. Cook, private communications "Origin of Dome Defects on GDP shells," LLNL internal memo, February 61994. 


\section{FIGURE CAPTIONS}

Fig. 1. The graded germanium-doped $\mathrm{CH}$ shell design for NIF ignition.

Fig. 2. The graded germanium-doped $\mathrm{CH}$ design allows rougher shell surface finish and a less strict surface smoothness standard as shown in the power spectrum. The new power spectrum allows six fold increases in power for modes greater than 23 .

Fig. 3. The amplification of sub-micrometer defects by $70 \mu \mathrm{m}$ thick coating on mandrels from two batches. The shells were coated at the same time. The batch to the right has consistently worse surface finish and was removed.

Fig. 4. The coating rates as a function of germanium concentration.

Fig. 5. The back-scattered scanning electron micrograph of the cross-section through the shell's equator. Two lighter-colored layers have germanium doping. The brightest layer contains higher germanium. The PAMS mandrel detached from the wall due to polishing.

Fig. 6. The contact radiograph image of graded Ge-doped shell. The boundary between PAMS mandrel and the un-doped $\mathrm{CH}$ is not distinct due to their densities are close to each other. The transmission versus shell radius plot is obtained by averaging thousands of radial line outs, like A-A' line shown here, to obtain the transmission plot versus radius shown in Fig. 5.

Fig. 7. The normalized transmission versus radius plot from quantitative radiograph. This graph is obtained by digitizing and normalizing the transmission intensities of the X-ray film plate. The 
zero transmission (full exposure) to the right is outside the shell. Each curvature presents a layer in the shell wall.

Fig. 8. Comparison of graded germanium layer thickness versus design values.

Fig. 9. The AFM traces of graded shell show good surface finish at $150 \mu \mathrm{m}$ thickness (left) and the power spectrum of the graded Ge shell meets the new NIF surface standard (right).

Fig. 10. The contact radiograph images show the mandrel has been removed at $305^{\circ} \mathrm{C}$ for $10 \mathrm{~h}$.

Fig. 11. The WYKO interferometer image of inner shell wall after mandrel was removed at $305^{\circ} \mathrm{C}$ for $20 \mathrm{~h}$. Typically, the root-mean-square surface (RMS) roughness is ranging from 1.1$6.5 \mathrm{~nm}$. This particular area has RMS roughness of $2.5 \mathrm{~nm}$. 


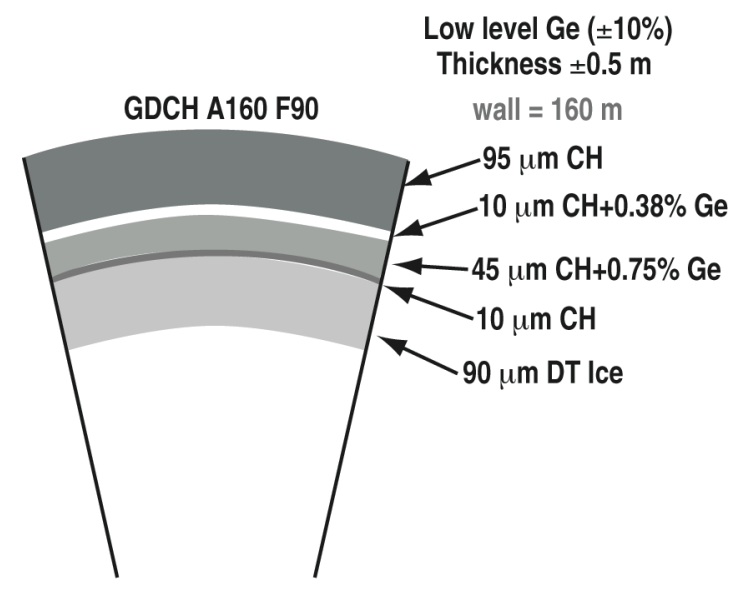

Chen, K.C. Fig. 1 


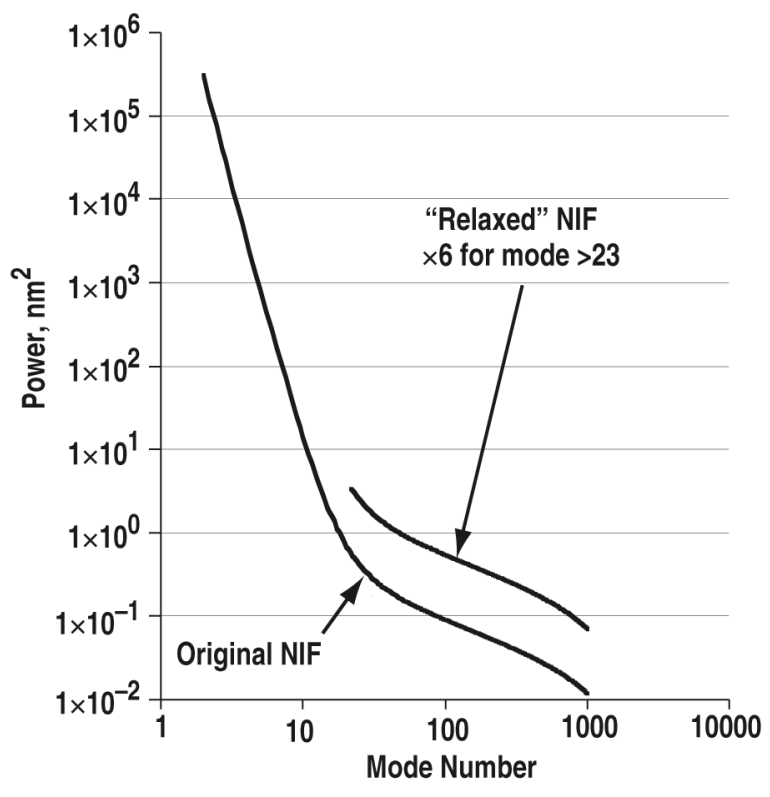

Chen, K.C. Fig. 2 


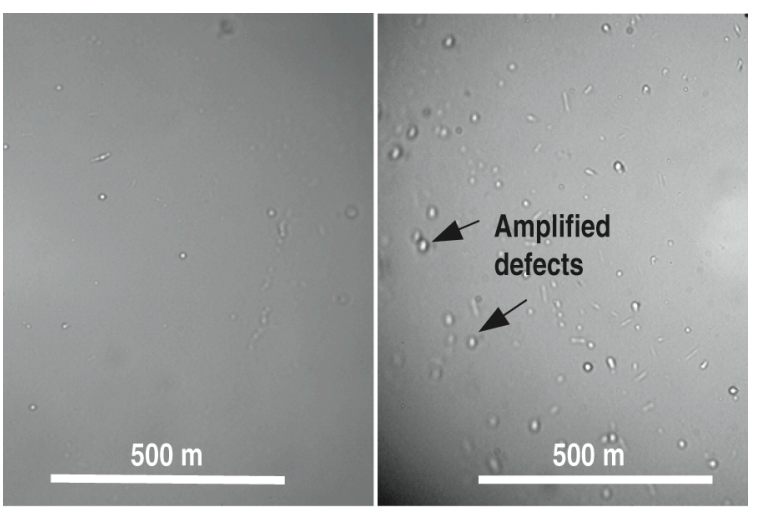

Chen, K.C. Fig. 3 


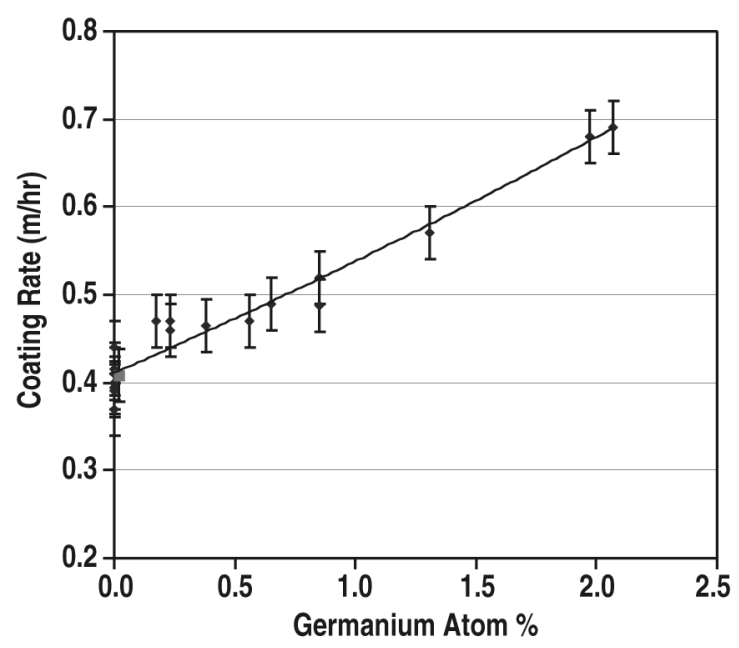

Chen, K.C. Fig. 4 


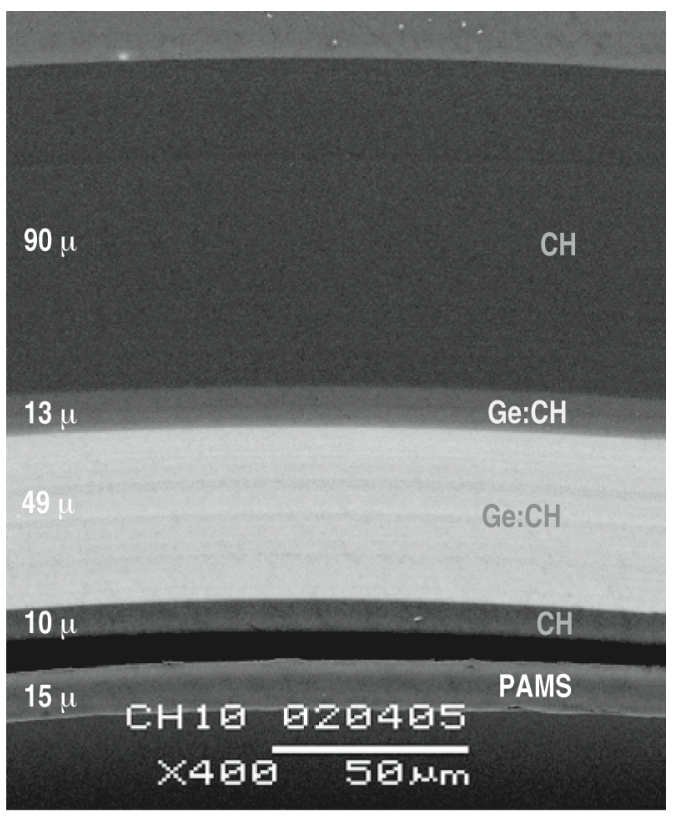

Chen, K.C. Fig. 5 


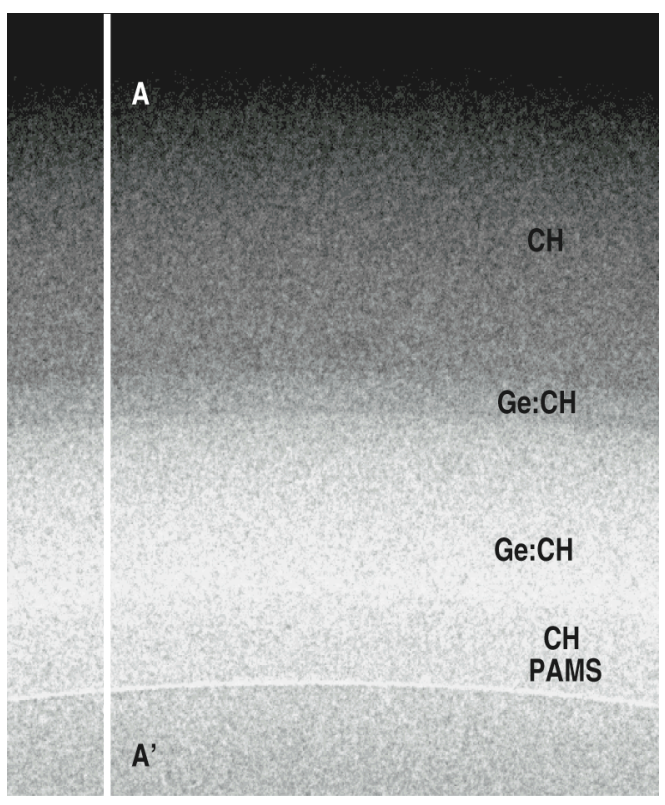

Chen, K.C. Fig. 6 


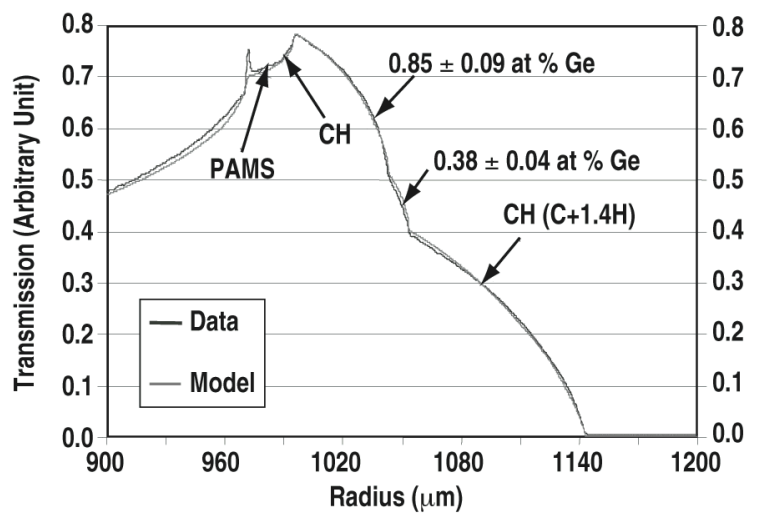

Chen, K.C. Fig. 7 


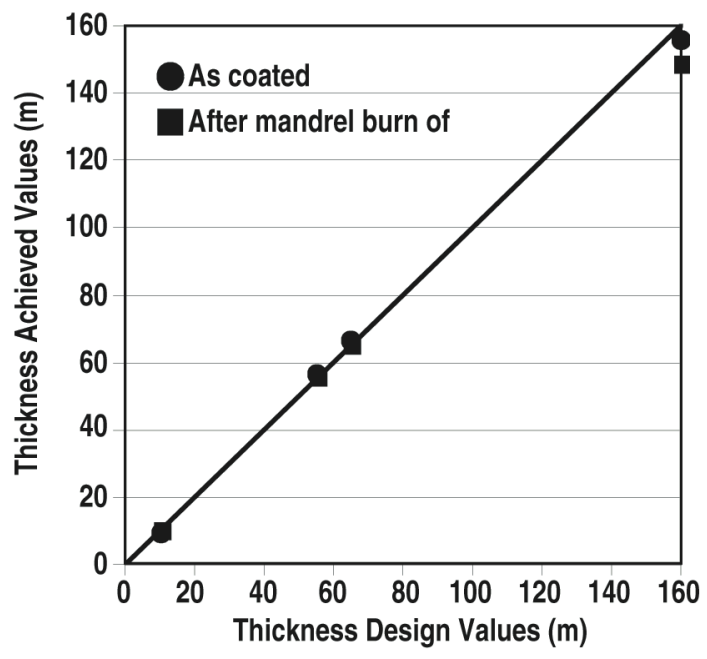

Chen, K.C. Fig. 8 

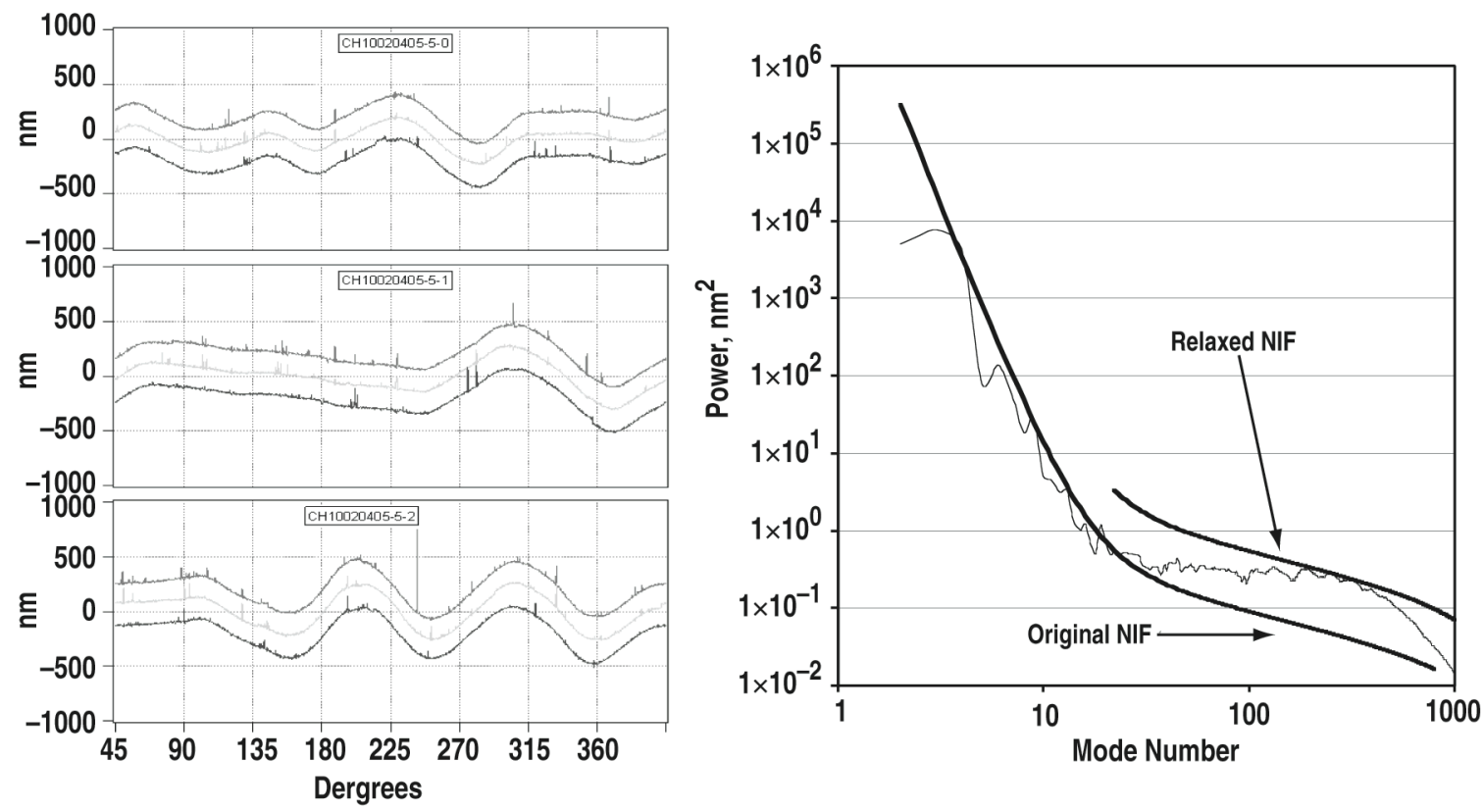

Chen, K.C. Fig. 9 


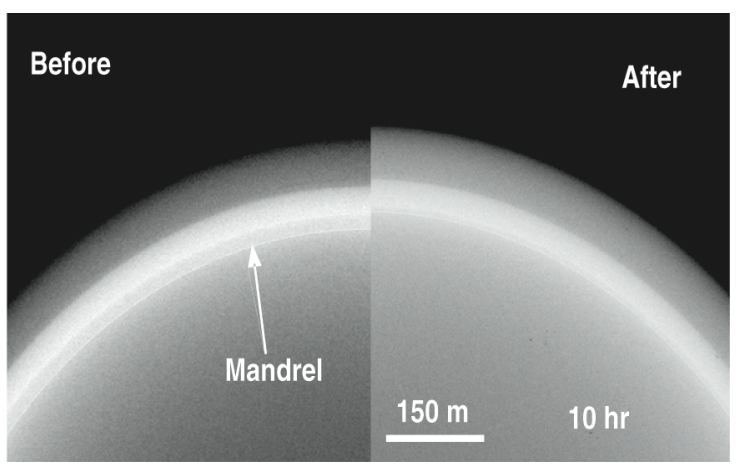

Chen, K.C. Fig. 10 


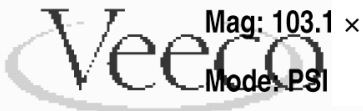

\begin{tabular}{|l|}
\hline Surface Statistics: \\
Ra: $1.87 \mathrm{~nm}$ \\
Rq: $2.50 \mathrm{~nm}$ \\
Rz: $31.79 \mathrm{~nm}$ \\
Rt: 37.23 \\
\\
Set-up Parameters: \\
Size: $736 ¥ 480$ \\
Sampling: $81.46 \mathrm{~nm}$ \\
\\
Processed Options: \\
Teams Removed: \\
Curvature and Tilt \\
Filtering: \\
None
\end{tabular}

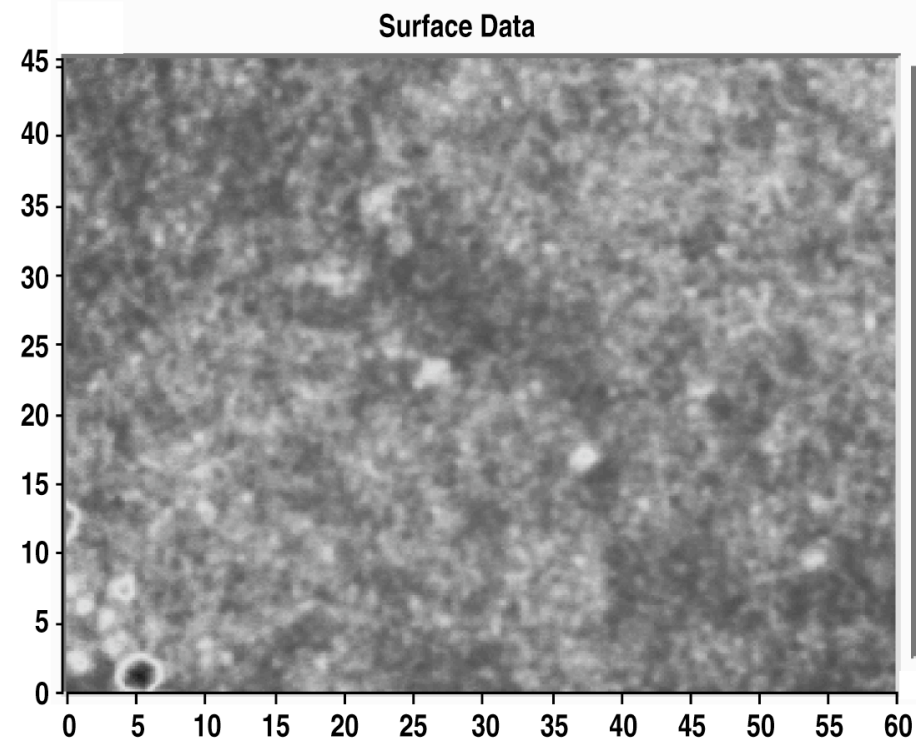

Chen, K.C. Fig. 11 